\title{
Assessment of Wake-Vortex Encounter Probabilities for Crosswind Departure Scenarios
}

\author{
${\text { Frank Holzäpfel* }{ }^{*} \text { and Jan Kladetzke }}^{\dagger}$ \\ DLR, German Aerospace Center, 82234 Oberpfaffenhofen, Germany
}

\author{
DOI: $10.2514 / 1 . C 000236$
}

\begin{abstract}
The WakeScene-D (Wake Vortex Scenarios Simulation Package for Departure) software package has been developed for comprehensive airspace simulations of takeoff and departure. WakeScene-D consists of modules that model traffic mix, aircraft trajectories, meteorological conditions, wake-vortex evolution, and potential hazard area. The software package estimates the probability to encounter wake vortices in different traffic and crosswind scenarios using Monte Carlo simulation in a domain ranging from the runway to an altitude of $3000 \mathrm{ft}$ above ground. A comparison with measured vortex tracks of about 10,000 departures from runway $25 \mathrm{R}$ of Frankfurt airport indicates good agreement of global wake-vortex transport characteristics in ground proximity. The standard departure situation employing a 2 min aircraft separation is compared with scenarios with reduced departure separations and various crosswind conditions. Comprehensive sensitivity analyses have been conducted that are briefly recapitulated. Effects related to departure-route combinations and wind-direction sectors are reported in more detail. Finally, an advanced scenario with an asymmetric crosswind criterion is introduced.
\end{abstract}

\section{Introduction}

A IRCRAFT-GENERATED wake vortices pose a potential risk to following aircraft in various flight phases, whereas most wakevortex encounters are reported for approach and landing and for takeoff and climb [1]. The International Civil Aviation Organization (ICAO) wake-vortex aircraft separation standards [2] established in the 1970s increasingly degrade aviation efficiency when traffic congestion limits airport capacity during landing and takeoff. Research has shown that the transport and persistence of wake vortices are highly dependent on meteorological conditions [3,4], so that in many cases the separation standards are overconservative. For single-runway operations, analyses [5-7] suggest that, above a certain crosswind threshold, vortices are blown out of the flight corridor and pose no further threat to following aircraft.

The European Union (EU) project CREDOS ${ }^{\ddagger}$ (CrosswindReduced Separations for Departure Operations) intends to demonstrate the operational feasibility of a concept of operations that uses measures of the prevailing crosswind component to allow temporary suspension of the need to apply wake turbulence separations between successive departing aircraft. The focus on the combination of crosswind and departures has significant advantages: The follower aircraft is still on the ground when the controller schedules the separation. So the controller always has the possibility to extend the separation without requiring the pilot to make a maneuver. This beneficial situation also reduces the time horizon for which crosswind conditions must be anticipated. Second, in contrast to arrival situations the leader aircraft is generally faster so that the actual separations tend to increase.

WakeScene-D (Wake Vortex Scenarios Simulation Package for Departure) [8] is an extension of WakeScene, which was developed for approach and landing and is described in detail in [9]. WakeScene-D estimates the probability to encounter wake vortices in different traffic and crosswind scenarios using Monte Carlo simulation in a domain ranging from the runway to an altitude of

Received 23 December 2009; revision received 4 March 2010; accepted for publication 4 May 2010. Copyright (C) 2010 by the American Institute of Aeronautics and Astronautics, Inc. All rights reserved. Copies of this paper may be made for personal or internal use, on condition that the copier pay the $\$ 10.00$ per-copy fee to the Copyright Clearance Center, Inc., 222 Rosewood Drive, Danvers, MA 01923; include the code 0021-8669/11 and \$10.00 in correspondence with the CCC.

${ }^{*}$ Research Scientist, Institute of Atmospheric Physics; frank. holzaepfel@dlr.de.

Institute of Robotics and Mechatronics.
$3000 \mathrm{ft}$ above ground. In cases with potential wake encounters all relevant parameters can be provided to VESA (Vortex Encounter Severity Assessment) [10,11], a tool developed by Airbus, which may subsequently perform detailed investigations of the severity of the encounter. WakeScene-D consists of elements that model traffic mix, aircraft trajectories, meteorological conditions, wake-vortex evolution, and potential hazard area. The process and data flows are controlled and evaluated by the MATLAB-based environment MOPS (Multi-Objective Parameter Synthesis) [12]. Within CREDOS WakeScene-D is used to support the definition of suitable crosswind criteria that allow reducing aircraft separations, to identify the sensitivity and interplay of the employed submodels and parameter combinations, and to support risk analyses taking into account a broad range of variables that determine the probability and risk of a wake-vortex encounter.

Related models have been developed for approach and landing:

1) WAVIR (wake-vortex-induced risk) [13] is capable of estimating frequencies of certain risk events in a given scenario.

2) ASAT (Airspace Simulation and Analysis for TERPS, where TERPS stands for Terminal Instrument Procedures) is a multifaceted computer tool for aviation-related simulations and safety evaluations that has not been specifically designed as a wake-vortex riskassessment model. Similar to WakeScene, ASAT has an interface to VESA that permits subsequent wake-vortex encounter severity assessment.

3) The Vortex Risk Analysis Tool has been employed for the risk assessment of the High Approach Landing System/Dual-Threshold Operation (HALS/DTOP) implemented at Frankfurt airport. HALS/ DTOP aims at increasing the capacity of the closely spaced parallel runway system by employing a second threshold displaced by $1500 \mathrm{~m}$ for the southern runway.

4) A comprehensive air traffic control wake-vortex safety and capacity-integrated platform has also been generated in the EU project ATC-Wake [14].

Reference [1] provides a comprehensive survey on operational concepts designated to increase airport capacity and the regulatory framework, which is relevant for the associated risk assessments as well as many other wake-vortex-related issues.

First, this paper briefly describes the operating sequence of WakeScene-D and the employed submodels. For a detailed description of WakeScene-D, including statements of the validation work performed for the submodels and databases we refer to [8].

tData available online at www.eurocontrol.int/eec/credos/ retrieved [25 March 2011]. 
Next, a reference scenario is introduced that shall represent the real current departure situation. Then the statistics achieved with reduced aircraft departure separations and different crosswind thresholds are discussed. The paper highlights a selection of the most interesting results found in the conducted comprehensive sensitivity analyses. The investigated parameters of these sensitivity analyses comprise effects related to different departure-route combinations, variations of flight-path adherence, different wake-vortex models, the development of aircraft separations during the departures, the sample size of the Monte Carlo simulations, aircraft-type combinations, aircraft takeoff weights, meteorological conditions, and airport operation times. Vortex tracks of about 10,000 departures collected during a six-month measurement campaign at Frankfurt airport are compared with WakeScene-D simulations and a comparison of the arrival and departure situation is conducted. On one hand, the sensitivity analyses help to increase the confidence in the software package and, on the other hand, they allow identifying the parameters that control encounter probabilities during takeoff and departure. In a next step the knowledge of these key parameters enables the optimization of criteria for reduced aircraft separations under favorable crosswind conditions. Partial and preliminary results of these investigations have already been reported [15]; a detailed description is available in [16].

\section{Survey on Operating Sequence and Employed Submodels}

The design, operating sequence and the employed submodels of WakeScene-D are described in detail in [8] and will here be recapitulated only briefly. Via simulation control [12] the types of the heavy generator aircraft (A300-600, A310, A330-300, A340-300, B747-400 and B777-200) and medium follower aircraft (A320, ATR 42-500, B737-300, and Bombardier CRJ), the departure routes (see Fig. 1), and a number of aircraft and pilot parameters are selected. In this study only pairings of heavy leading aircraft followed by medium aircraft are considered. The traffic mix is modeled according to the statistics of Frankfurt airport in 2006 [17], where the respective aircraft-type combinations are varied randomly. The aircraft trajectory model [18] provides time, speed, position, attitude, lift and mass of generator and follower aircraft along the flight paths. Based on vertical profiles of wind speed and direction, air density, virtual potential temperature, and eddy dissipation rate and aircraft position, speed, attitude, lift, and span, the deterministic two-phase wakevortex decay model (D2P, $[19,20])$ simulates the development of wake-vortex trajectories, circulation, vortex core radius, and attitude of wake-vortex axes. The employed realistic one-year meteorological database has been produced for the Frankfurt terminal area with the mesoscale weather-forecast model system NOWVIV (nowcasting wake-vortex impact variables [21]). The simplified hazard area prediction model (SHAPe, [22]) computes the distance between wake vortex and follower aircraft and may discriminate between potentially critical cases and cases where safe and undisturbed flight is guaranteed. From all these data criteria like

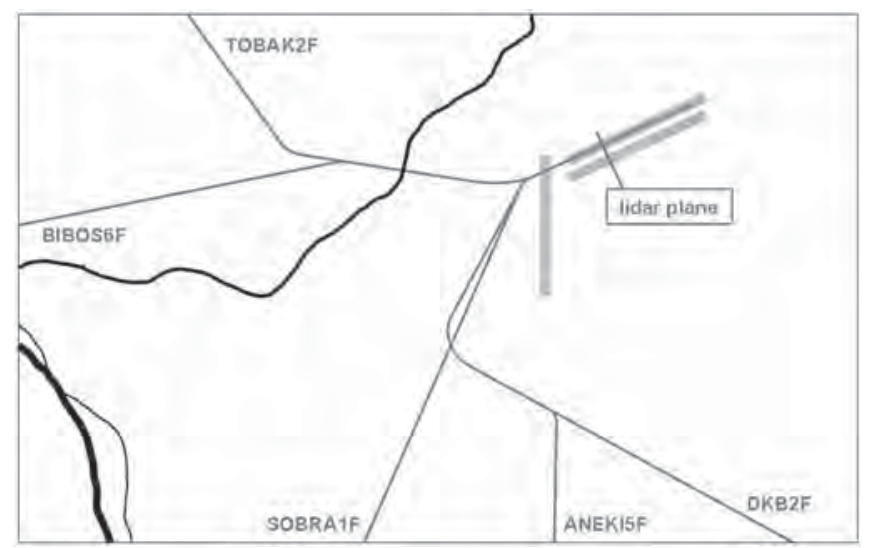

Fig. 1 Runways, SID routes, and lidar measurement plane. minimal distance between wake vortex and follower aircraft, the respective vortex circulation and height are computed and statistically analyzed. Finally, data needed for further investigations with VESA (Vortex Encounter Severity Assessment) are deduced and stored. The preselection of cases of interest within WakeScene-D reduces the computing effort for VESA significantly. The results are optionally visualized in graphs of the statistics, 2-D and 3-D views or animations of the departures of subsequent aircraft.

WakeScene-D simulates departures from runway 25R at Frankfurt international airport (see Fig. 1). The selection of the configuration of the employed submodels and parameters is always a tradeoff between a realistic as possible setup in order to include all relevant effects and a more generic setup that enables transferring the results to other airports. In this investigation the aircraft employ the five different standard instrument departure (SID) routes displayed in Fig. 1 with equal probability although in praxis the southerly departure routes are only used if strong northerly winds prevent the use of runway 18. Alternatively a straight departure route is also considered. Along the standard departure routes, curved flight also has to be taken into account. Therefore, wake-vortex evolution is predicted within control gates that are released along the flight path of the wake-vortex generator aircraft in predefined time increments of $5 \mathrm{~s}$. The gates' orientations are perpendicular to the aircraft true heading and perpendicular to the flight-path angle (see [8]). For the identification of potential encounters wake-vortex tracks and aircraft tracks are interpolated between the gates.

\section{Reference Scenario}

The described scenario serves as a reference that shall represent the real current departure situation. The working hypothesis assumes that the encounter frequencies estimated for reduced separations under appropriate crosswind conditions shall not be higher than in the reference scenario. Note that the encounter frequencies denote the fraction of encounters within a given scenario. To obtain the absolute probability of encounters in a scenario, the encounter frequency must be multiplied by the frequency of the considered crosswind situation.

The reference scenario employs a sample size of 1,000,000 aircraft pairings. All follower aircraft obey the $120 \mathrm{~s}$ ICAO separation. The following parameters of the generator and the follower aircraft are randomly distributed: start point, takeoff weight, thrust mode (TOGA take off go around or FLEX take off (reduced) thrust), departure-route combination, trajectory deviation, and pilot delay parameter. We employ randomly chosen meteorological data of the NOWVIV one-year database within the operational hours of Frankfurt airport (0600-2300 hrs). Furthermore, cases with tailwinds above $5 \mathrm{kt}$ are excluded. The constraints regarding operational hours and tailwind are also applied for all other investigated cases.

Figure 2 singles out the fraction of departures $(70,167$ cases or $7.0 \%$ ) in which the follower aircraft approach the vortices closer than $50 \mathrm{~m}$ and the vortices still have at least a circulation of $100 \mathrm{~m}^{2} / \mathrm{s}$. These cases potentially correspond to an encounter and should be understood as cases of interest or potential encounters. Detailed investigations with VESA are necessary to identify the risks related to such potential encounters. For convenience we call these cases simply encounters without regard to the real connected risks.

Remarkably, 66\% of these "encounters" are restricted to heights below $300 \mathrm{ft}$ above ground (see Fig. 2a). Within this altitude range clearance of the flight corridor by descent and advection of the vortices is restricted: stalling or rebounding vortices may not clear the flight path vertically and weak crosswinds may be compensated by vortex-induced lateral transport [20]. This culmination of vortex encounters at low altitudes indicates that the sought crosswind criterion could be limited to this height range, which would substantially facilitate the implementation of an operational system.

Further, minor peaks at 1300 and $1800 \mathrm{ft}$ occur in Fig. 2a. These minor peaks can be attributed to flight-path changes that increase the encounter risk compared with approximately parallel flight of the leader and follower aircraft. Figure 3 exemplifies a typical situation: At about $1500 \mathrm{ft}$ the leading aircraft reduces thrust and thus the climb 


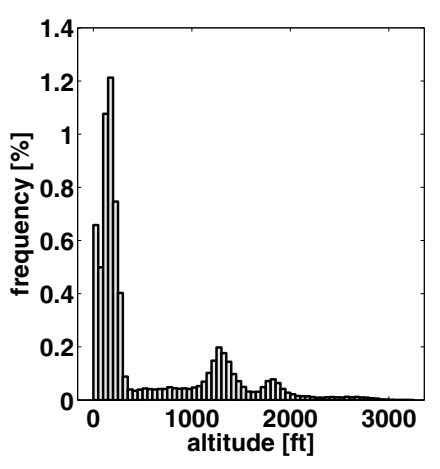

a)

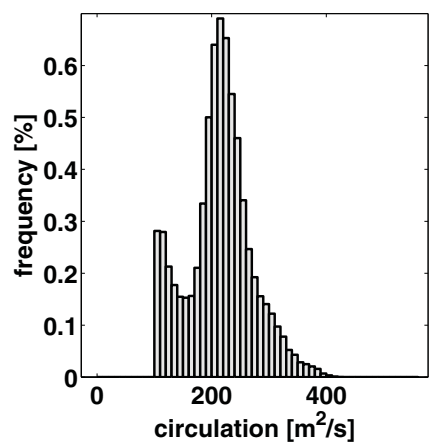

d)

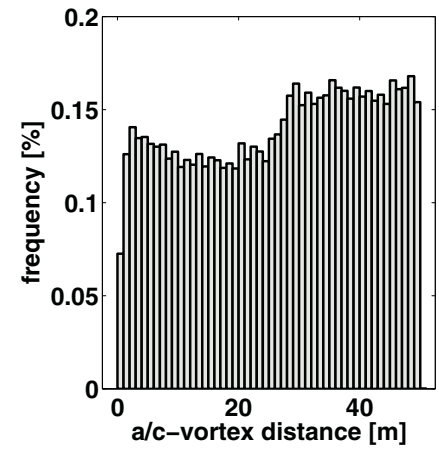

b)

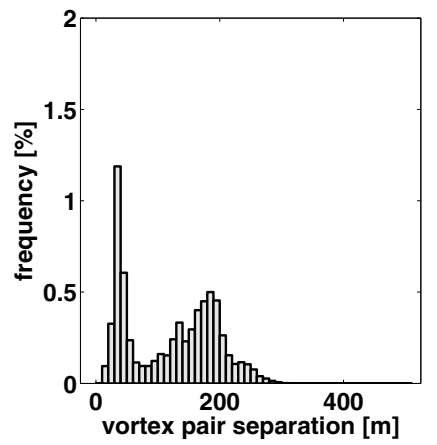

e)

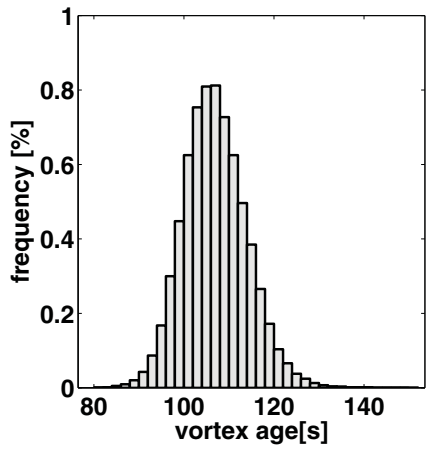

c)

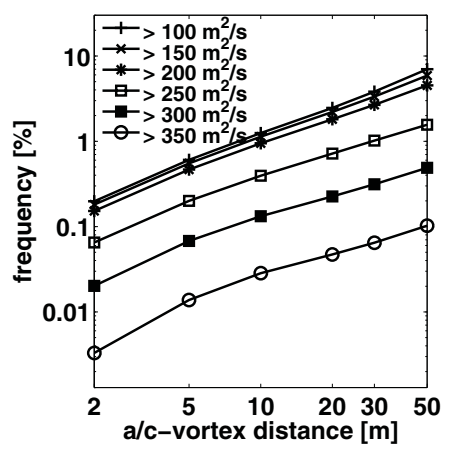

f)

Fig. 2 Statistics of cases of interest in the reference scenario: a) aircraft altitude, b) distance between follower aircraft and wake vortex, c) vortex age, d) vortex circulation, e) vortex pair separation, and f) encounter frequencies dependent on distance to the vortex and circulation.

rate; at the same time it initiates a turn toward a southerly direction. The combination of this flight-path diversion with a strong headwind component that counteracts the vortex descent and a southerly wind direction leads to the displayed encounter at $1250 \mathrm{ft}$. The second cluster of encounters at $1800 \mathrm{ft}$ is related to the resumption of climb when the aircraft reach the final climb speed. A number of other combinations of flight-path diversions and adverse wind directions have been identified, both for identical and different departure routes of the leader and follower aircraft.

Figure $2 \mathrm{~b}$ reveals that within the $50 \mathrm{~m}$ distance the encounter frequency depends only weakly on the separation between aircraft and wake vortices. Figure $2 \mathrm{c}$ and $2 \mathrm{~d}$ indicate a considerable range of vortex ages between 80 and $150 \mathrm{~s}$ corresponding to vortex strengths between 100 and $430 \mathrm{~m}^{2} / \mathrm{s}$. The irregular circulation distribution in Fig. $2 \mathrm{~d}$ is mostly related to differing vortex decay characteristics of the different generator aircraft types in combination with different decay rates in ground proximity and aloft. Figure $2 \mathrm{e}$ illustrates that in $19 \%$ of the encounters the vortices still approximately retain their initial vortex spacings ranging from 34.5 to $50.6 \mathrm{~m}$ for the selected vortex generator aircraft types. The cluster of vortex separations beyond $100 \mathrm{~m}$ represents the range typically occurring after vortex rebound in ground proximity.

Figure $2 \mathrm{f}$ displays encounter frequencies dependent on the minimum distance between the follower aircraft and the vortex during the whole departure and the respective circulation, $\Gamma$. The frequency of encounters with $\Gamma>100 \mathrm{~m}^{2} / \mathrm{s}$ reduces from $7.0 \%$ for vortex distances below $50 \mathrm{~m}$ to $0.20 \%$ for distances below $2 \mathrm{~m}$. For circulations stronger than $350 \mathrm{~m}^{2} / \mathrm{s}$ the encounter frequencies are $0.10 \%$ for vortex distances below $50 \mathrm{~m}$ and reduce to $0.0037 \%$ (37 cases of 1,000,000 departures) for distances below $2 \mathrm{~m}$.

The considered range of distances to the vortex and circulation strengths was chosen such that, on one hand, no cases of interest are

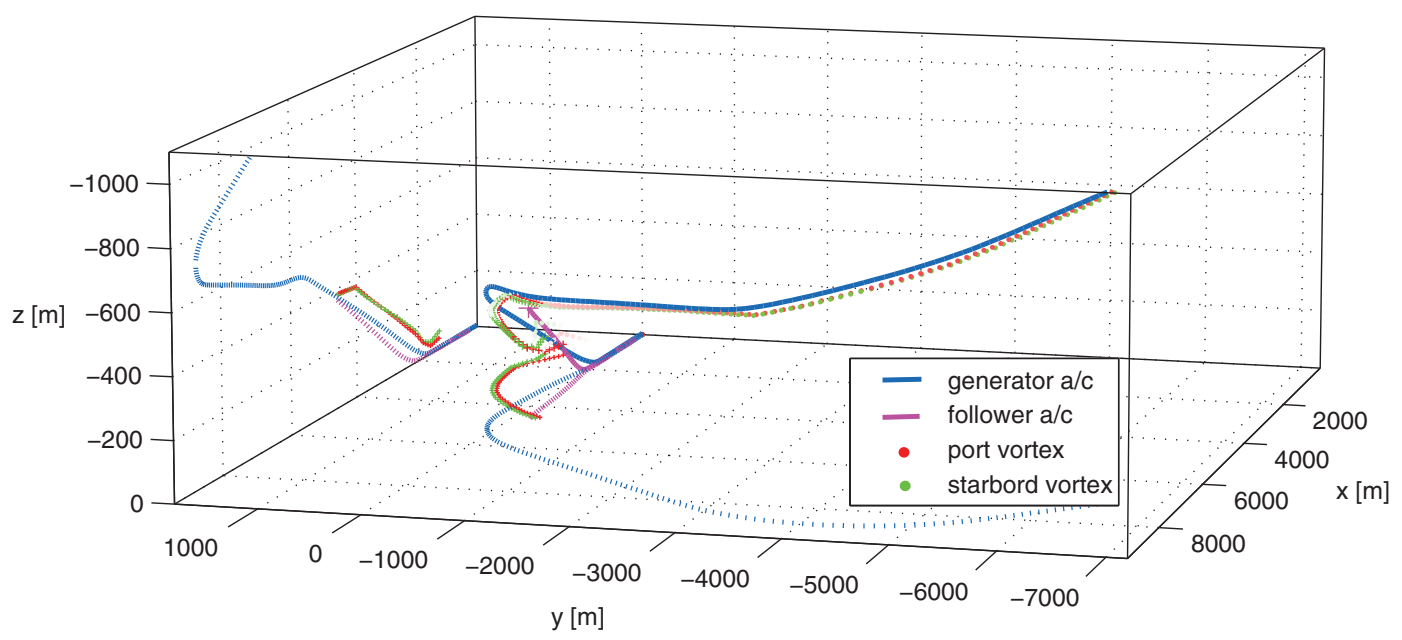

Fig. 3 Perspective view of trajectories of wake-generating aircraft (blue) and follower aircraft (magenta) together with wake-vortex positions (starboard vortex green, port vortex red). Projections of aircraft and vortex positions on vertical and horizontal planes are added for convenience. 
missed and, on the other hand, the rarest strong encounters are captured. Note that the weakest potential encounters $\left(\Gamma>100 \mathrm{~m}^{2} / \mathrm{s}\right.$, aircraft $(\mathrm{a} / \mathrm{c})$-vortex distance $<50 \mathrm{~m})$ in many cases may not lead to any perceptible interference. On the other hand, close encounters on the order of 2 to $5 \mathrm{~m}$ are almost not feasible, because they are impeded by wake-vortex-induced aircraft reactions. In this approach factors like encounter angles, flight attitude and altitude of the follower aircraft are neglected. Therefore, only VESA (which fully considers the encounter situation, including the interaction of aircraft and wake vortex) may really evaluate the related risks. Because VESA investigations are out of the scope of this paper, the metrics of Fig. $2 \mathrm{f}$ are used to relatively compare the risks of the different scenarios. A target scenario is considered safe when all these joint frequencies are below the reference scenario.

\section{Crosswind Dependency}

Statistics of encounter frequencies and encounter conditions have been produced for 60 and $90 \mathrm{~s}$ departure separations and crosswind thresholds from 0 to $10 \mathrm{kt}$ in $2 \mathrm{kt}$ increments, respectively. All other parameters correspond to the reference scenario. The crosswind criterion is met when the crosswind at $10 \mathrm{~m}$ height above ground exceeds a predefined threshold. This crosswind criterion has been selected for the following reasons:

1) Ten meters is the standard height for surface wind measurements and thus constitutes the operationally simplest approach for crosswind dependent reduced separations.

2) Most encounters are restricted to heights below $300 \mathrm{ft}$ above ground.

3) An investigation of wind conditions at Frankfurt airport [23] reports a 95\%-correlation of the crosswind at $100 \mathrm{~m}$ height with the $10 \mathrm{~m}$ wind measurement.

Three independent analyses of field measurement data of wake vortices generated by departing aircraft in an altitude range from 0 to $400 \mathrm{~m}$ at Frankfurt airport have been performed within the CREDOS project to determine crosswind thresholds that ensure that the wake vortices have left a safety corridor at certain aircraft separation times [23-25]. Although the three analyses employ different assumptions on the safety corridor definition and size, the employed confidence levels, and the crosswind measurement sources and definitions, they consistently yield crosswind thresholds on the order of $4 \mathrm{~m} / \mathrm{s}$ to make sure that the wake vortices have escaped a safety corridor at a vortex age of $60 \mathrm{~s}$ with a high probability based on good quality wind measurements. Note that such studies do not allow quantifying the related risks and setting the risks into relation to the current ICAO operations.

The corresponding WakeScene-D results for aircraft separations of $60 \mathrm{~s}$ and crosswinds above $8 \mathrm{kt}(4.1 \mathrm{~m} / \mathrm{s})$ are displayed in Fig. 4. The overall frequency of encounters of $3.1 \%(31,239$ cases $)$ is clearly below the corresponding frequency of $7.0 \%$ of the reference scenario. Figure 4 shows in agreement with the experimental results that the strong crosswind in ground proximity is outmost effective. The remaining 56 encounters below $300 \mathrm{ft}$ can be almost neglected compared with the corresponding 45,962 encounters in the reference scenario. Now the peak at $1800 \mathrm{ft}$ related to flight-path diversions clearly dominates the scenario.

The encounter synopsis in Fig. 4f indicates that despite of the reduction of the overall encounter frequencies the encounters with circulations stronger than $350 \mathrm{~m}^{2} / \mathrm{s}$ are still two to four times more frequent than in the reference scenario in Fig. $2 \mathrm{f}$. This can be explained by the halved time for vortex decay. Two facts may potentially reduce the hazard of the current encounters compared with the reference scenario. The encounters occur at sufficiently high altitudes to provide ample time for pilots to recover. The encounter angles are increased, which could potentially reduce adverse effects for the follower aircraft.

Figure 5 and 6 depict the so-called encounter angles $\gamma$ and $\psi$, which denote the inclination angle and the azimuth angle between vortex axis and flight path of the follower aircraft, respectively. Negative inclination angles $\gamma$ denote situations where the aircraft approach the vortex from below. Negative azimuth angles $\psi$ refer to encounters from the left, i.e., the aircraft hit in general the port vortex.

Figure 5 shows the encounter angles with color-coded circulation values for the reference scenario. The predominantly negative inclination angles $\gamma$ below $300 \mathrm{ft}$ correspond to cases where the aircraft approach the wake vortices from below after the vortex rebound. Because of the ground-induced decay the corresponding circulation values are relatively low.

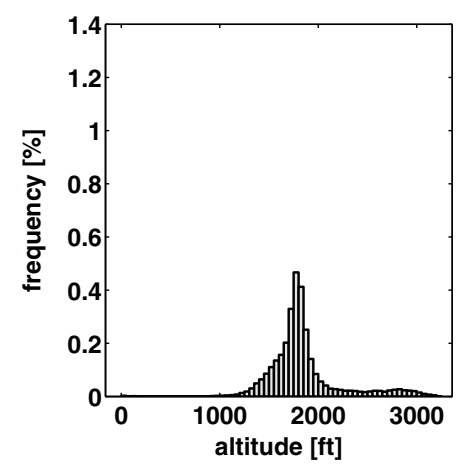

a)

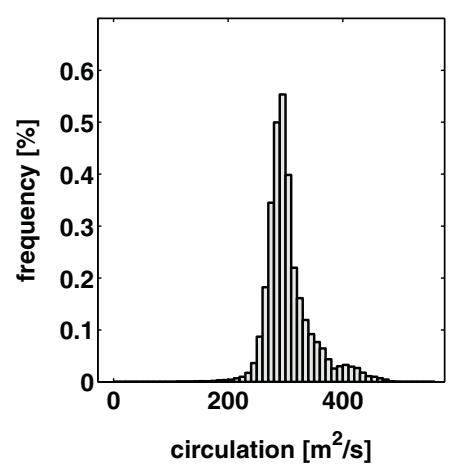

d)

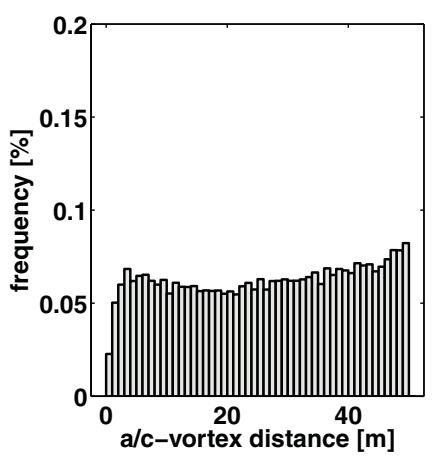

b)

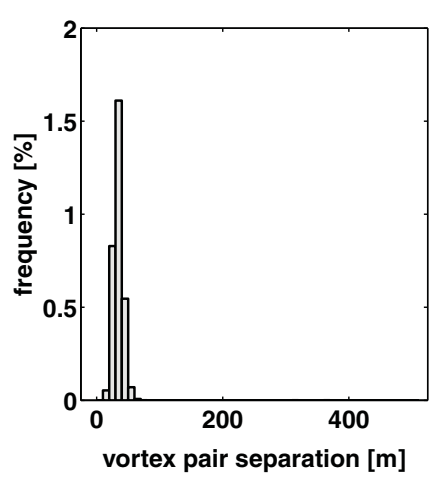

e)

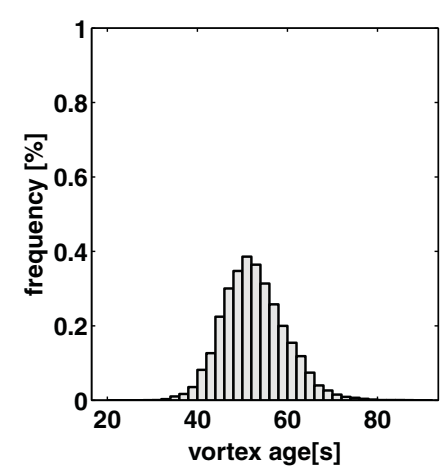

c)

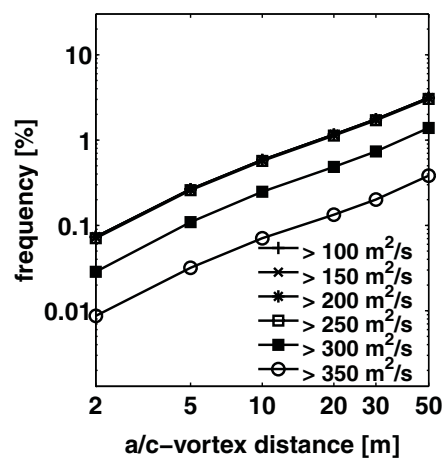

f)

Fig. 4 Statistics of cases of interest for aircraft separations of $60 \mathrm{~s}$ and a crosswind threshold of $8 \mathrm{kt}$. 

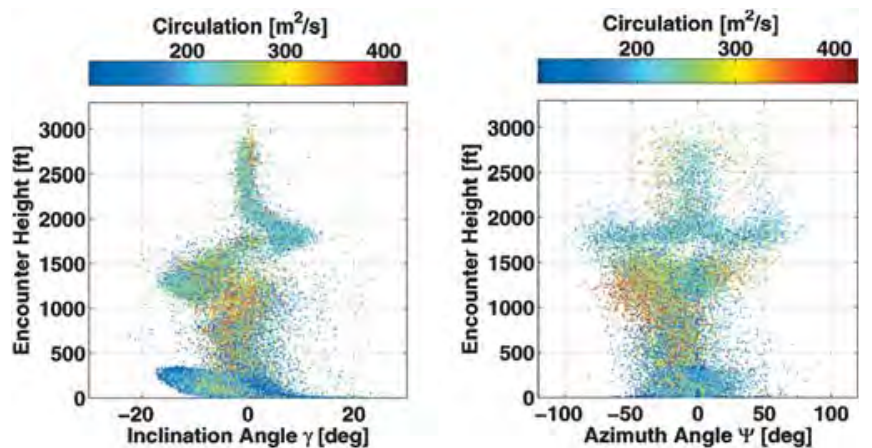

Fig. 5 Encounter angles $\gamma$ (inclination angle) and $\psi$ (azimuth angle) dependent on altitude with color-coded circulation for the reference scenario.
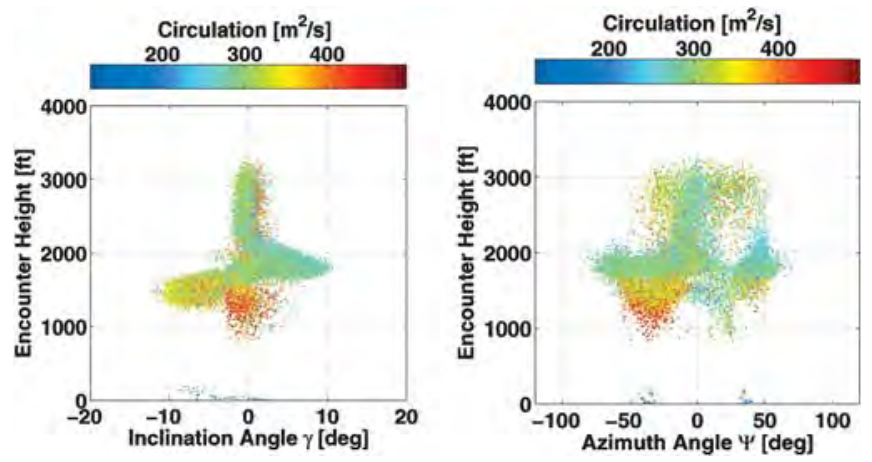

Fig. 6 Encounter angles dependent on altitude with color-coded circulation for $60 \mathrm{~s}$ aircraft separations with crosswinds above $8 \mathrm{kt}$.

Aloft the inclination angles, on average, are slightly negative. This can be explained to some extent by the steeper climb rates of the follower aircraft and to some extent by reduced descent rates of aged wake vortices. At about $1500 \mathrm{ft}$ the aircraft reduce the climb rate in order to accelerate. Below that altitude range the aircraft with higher climb rates encounter less inclined vortices $(\gamma<0$, see Fig. 3). Inversely, positive inclination angles (encounter from above) occur in the altitude range where the follower aircraft with lower climb rates encounter wake vortices that were generated by aircraft that have already resumed climb when they have reached the final climb speed.

The azimuth angles $\psi$ are, on average, negative. This can probably be attributed to the more frequent southwesterly winds. Crosswinds directed from port to starboard are tilting the vortices in the azimuthal direction, because the longer residence times of older vortex segments lead to larger transport distances. The turns around 1500 and $2000 \mathrm{ft}$ (see Fig. 1) lead to increased encounter azimuth angles with positive and negative signs, depending on the departure-route combinations and the wind direction (see Fig. 3).

Figure 6 shows the encounter angles for $60 \mathrm{~s}$ aircraft separations with crosswinds above $8 \mathrm{kt}$. Now encounters at low altitudes have almost completely disappeared. Most of the remaining encounters are occurring above $1000 \mathrm{ft}$ and can be explained by the flight-path changes discussed above. A remarkable concentration of encounters with strong vortices between 1000 and $1700 \mathrm{ft}$ occurs with inclination angles centered on zero and azimuthal angles around $30 \mathrm{deg}$. These strong encounters mainly occur if the leading aircraft follows a southerly departure route. In these cases the leading aircraft have already initiated a turn without reducing the climb rate and southwesterly winds compensate vortex-induced descent.

Table 1 provides a synopsis of the encounter frequencies for the investigated crosswind and departure separation scenarios. The total encounter frequency (distance between aircraft and vortex is smaller than $50 \mathrm{~m}$ and the circulation is larger than $100 \mathrm{~m}^{2} / \mathrm{s}$ ) of the reference scenario of $7 \%$ is almost doubled when the aircraft separation is reduced by $30 \mathrm{~s}$ and it is almost tripled when the aircraft separation is halved from 120 to $60 \mathrm{~s}$. For crosswinds stronger than $4 \mathrm{kt}(6 \mathrm{kt})$, the total encounter frequency of the $90 \mathrm{~s}(60 \mathrm{~s})$ aircraft separations is reduced again to almost $50 \%$ of the reference scenario. Further increased crosswinds only marginally reduce the encounter frequencies. This can be explained by the fact that less than $3 \%$ $(1.5 \%)$ of the encounters occur below $300 \mathrm{ft}$ for crosswinds stronger than $6 \mathrm{kt}(4 \mathrm{kt})$ and aircraft separations of $60 \mathrm{~s}(90 \mathrm{~s})$. Stronger crosswinds at $10 \mathrm{~m}$ above ground are not effective in reducing the encounter frequencies at altitudes above $300 \mathrm{ft}$.

Encounter frequencies at $90 \mathrm{~s}(60 \mathrm{~s})$ aircraft separation below $300 \mathrm{ft}$ already fall below the frequencies of the reference scenario for crosswinds above $2 \mathrm{kt}(4 \mathrm{kt})$. At $4 \mathrm{kt}(6 \mathrm{kt})$ crosswinds and $90 \mathrm{~s}(60 \mathrm{~s})$, aircraft separations encounter frequencies are reduced to only about $1.2 \%(2.2 \%)$ of the reference scenario. Another strong reduction to three (56) encounters below $300 \mathrm{ft}$ is obtained with crosswinds above $6 \mathrm{kt}(8 \mathrm{kt})$ at the $90 \mathrm{~s}(60 \mathrm{~s})$ aircraft separations. Further reductions due to increased crosswinds are negligible.

For worst-case encounters (vortex distance smaller than $2 \mathrm{~m}$ and circulation larger than $350 \mathrm{~m}^{2} / \mathrm{s}$ ) the frequency is increased by a factor of 6 (30) when the aircraft separation is reduced from 120 to $90 \mathrm{~s}(60 \mathrm{~s})$. Encounter frequencies below the reference scenario at $90 \mathrm{~s}(60 \mathrm{~s})$ aircraft separations are only achieved with crosswinds stronger than $8 \mathrm{kt}(10 \mathrm{kt})$.

In conclusion, crosswinds are already very effective at reducing encounter frequencies close to the ground for crosswinds stronger than $4 \mathrm{kt}(6 \mathrm{kt})$ at $90 \mathrm{~s}(60 \mathrm{~s})$ aircraft separations. As a consequence, the encounters at higher altitudes become more prominent. Because of the reduced time for vortex decay worst-case encounter frequencies aloft are not reduced very effectively by increasing crosswinds.

Figure 7 shows the frequencies of the crosswinds in the meteorological database in $0.5 \mathrm{kt}$ increments (all crosswinds [CWs]) and the respective encounter frequencies versus crosswind speed for aircraft separations of 60,90 , and $120 \mathrm{~s}$. The left plot displays absolute frequencies, and the relative frequencies shown on the right are normalized to $100 \%$.

Figure 7 indicates that the highest encounter frequencies are not observed for zero crosswinds. For the scenarios with 120 and $90 \mathrm{~s}$ departure separations, they occur instead around crosswinds of \pm 1 to $\pm 1.5 \mathrm{kt}$. If the aircraft separation is reduced to $60 \mathrm{~s}$ the most critical crosswinds amount to $\pm 2.5 \mathrm{kt}$. This is due to the fact that weak crosswinds may compensate the vortex-induced lateral propagation speed of wake vortices generated in ground proximity such that the luff vortex is hovering above the runway [20]. For the $60 \mathrm{~s}$ separation the critical crosswind magnitude is higher, because the crosswind has less time to transport the vortices out of the flight corridor.

Table 1 Synopsis of encounter frequencies for different aircraft separations and crosswind scenarios

\begin{tabular}{|c|c|c|c|c|c|c|c|c|c|c|c|c|c|}
\hline & \multicolumn{13}{|c|}{ Scenario } \\
\hline & \multirow{2}{*}{$\frac{\text { All CWs }}{120 \mathrm{~s}}$} & \multicolumn{2}{|c|}{ All CWs } & \multicolumn{2}{|c|}{$\mathrm{CW}>2 \mathrm{kt}$} & \multicolumn{2}{|c|}{$\mathrm{CW}>4 \mathrm{kt}$} & \multicolumn{2}{|c|}{$\mathrm{CW}>6 \mathrm{kt}$} & \multicolumn{2}{|c|}{$\mathrm{CW}>8 \mathrm{kt}$} & \multicolumn{2}{|c|}{$\mathrm{CW}>10 \mathrm{kt}$} \\
\hline & & $90 \mathrm{~s}$ & $60 \mathrm{~s}$ & $90 \mathrm{~s}$ & $60 \mathrm{~s}$ & $90 \mathrm{~s}$ & $60 \mathrm{~s}$ & $90 \mathrm{~s}$ & $60 \mathrm{~s}$ & $90 \mathrm{~s}$ & $60 \mathrm{~s}$ & $90 \mathrm{~s}$ & $60 \mathrm{~s}$ \\
\hline Total encounter frequency, $\%$ & $7.0^{\mathrm{a}}$ & 12.8 & 19.9 & 7.5 & 17.7 & $3.7^{\mathrm{b}}$ & 8.3 & 2.6 & $3.8^{\mathrm{b}}$ & 2.2 & 3.1 & 1.9 & 2.7 \\
\hline Encounter frequency below $300 \mathrm{ft}, \%$ & $4.6^{\mathrm{a}}$ & 9.4 & 15.8 & $2.9^{\mathrm{b}}$ & 13.1 & 0.057 & $3.5^{\mathrm{b}}$ & 0.0003 & 0.10 & 0.0002 & 0.0056 & 0.0 & 0.0044 \\
\hline Worst-case encounter frequency, \% & $0.0037^{\mathrm{a}}$ & 0.023 & 0.11 & 0.011 & 0.056 & 0.0073 & 0.020 & 0.0041 & 0.010 & $0.0026^{\mathrm{b}}$ & 0.0086 & 0.0017 & $0.0025^{\mathrm{b}}$ \\
\hline
\end{tabular}

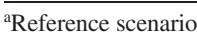

${ }^{\mathrm{b}}$ Encounter frequencies below the reference scenario. 

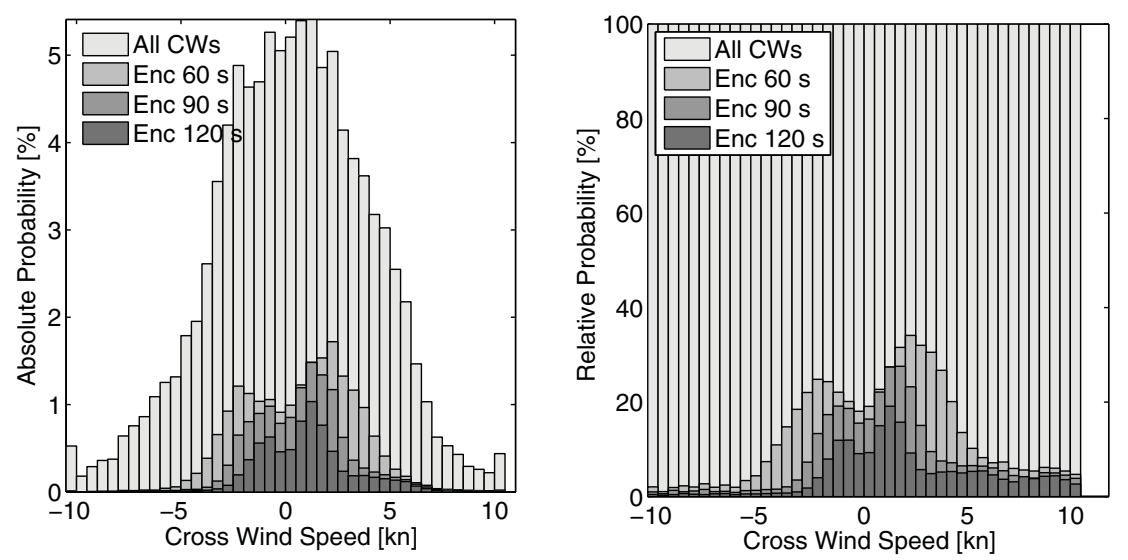

Fig. 7 Crosswind distribution in $0.5 \mathrm{kt}$ increments and respective absolute encounter frequencies for different aircraft separations (left) and relative encounter frequencies (right). Winds blowing from the port side are positive.

Figure 7 right indicates that for the $120 \mathrm{~s}$ separation crosswinds above $2.5 \mathrm{kt}$ do not significantly reduce the relative encounter frequencies. For the $90 \mathrm{~s}$ separation this is the case above about $4 \mathrm{kt}$ and for the $60 \mathrm{~s}$ separation the corresponding threshold is at about $6 \mathrm{kt}$. Beyond these thresholds the encounters at high altitudes related to flight-path diversions constitute the dominant risks.

Somewhat surprisingly, the histograms are not symmetric. Note that at -5 to $-5.5 \mathrm{kt}$ the relative encounter frequency for $60 \mathrm{~s}$ separations is already lower than the encounter frequency for 5 to $5.5 \mathrm{kt}$ for the $120 \mathrm{~s}$ reference scenario. Several reasons for the asymmetry can be identified:

1) The realistic meteorological database contains distributions of wind speed and direction, which are not only the result of predominant synoptic patterns, but are also influenced by the orography in the vicinity of the airport, in particular the Taunus mountain ridge.

2) The winds aloft generally deviate from the winds at $10 \mathrm{~m}$ altitude.

3) The departure routes are not symmetric with respect to the runway.

4) The most important and fundamental effect, however, is related to the turning of the wind direction to the right with increasing height (Ekman spiral). This effect is described in more detail in Sec. VI.B.

\section{Comparison with Field Measurement Data}

The validation activities for the individual submodels and databases of WakeScene-D and an estimation of the related uncertainties are described in [8]. Here, we perform a global comparison of wake-vortex transport characteristics achieved with long-term measurements and WakeScene-D simulations. Note that this comparison assumes that the employed data sample is sufficiently large to provide converged wake-vortex transport statistics in a climatological sense. During the six months CREDOS measurement campaign EDDF-2, vortex tracks of about 10,000 departures from runway 25R of Frankfurt airport were collected with the WindTracer lidar [25]. The lidar measurement plane was situated $2961 \mathrm{~m}$ from the threshold of runway 25R (see Fig. 1) where 99\% of the vortices were measured at heights below $135 \mathrm{~m}$. Wake vortices that might have been advected from runway $25 \mathrm{~L}$ to $25 \mathrm{R}$ are not part of the data set.

To mimic the lidar measurements with WakeScene-D we have simulated 10,000 departures with randomly chosen aircraft types and meteorological data. Wake-vortex predictions are interpolated within the lidar measurement plane. The lidar scan pattern leads to vortex observations roughly each $8 \mathrm{~s}$. To provide similar visual impressions of the scatter plots the WakeScene-D wake-vortex data are also plotted each $8 \mathrm{~s}$ where the instant for the first data point is varied randomly.

Figure 8 shows scatter plots of lateral positions of the port vortex against time based on the lidar measurements and WakeScene-D simulations. Additionally, the medians and distributions for one to three standard deviations are plotted. The comparison of the measurements (left) to the simulated lidar data (center) indicates that the domain covered by the lidar constitutes a subdomain of the real wake-vortex transport distances. Zooming the WakeScene-D simulation data on the area covered by the lidar (right) reveals an excellent agreement between measured and simulated lateral vortex transport characteristics. The main differences are related to shorter lidar observation times caused by a loss of the coherent vortex structure during the decay. This good agreement indicates that WakeScene-D supports investigating realistic wake-vortex behavior in domains and height ranges that are far out of reach of measurements. Because the modelling of wake-vortex transport in ground proximity is quite complex it could be assumed that the agreement with observations would be even better at higher altitudes.

\section{Sensitivity Studies}

Comprehensive sensitivity analyses regarding the impact of various submodels and parameter selections have been performed. First, a selection of the most interesting results is discussed. Then a
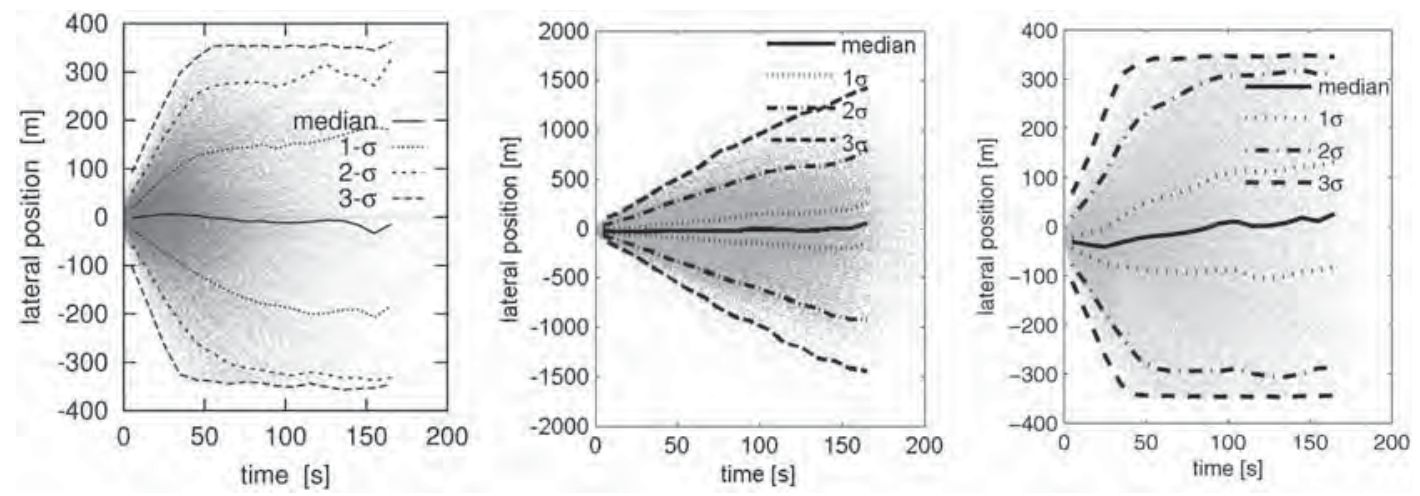

Fig. 8 Scatter plots and statistical distributions of lateral positions of the port vortices against time for 10,000 departures. Field measurement data (left) and WakeScene-D predictions within different domains (center and right). 
survey on the key results of the remaining sensitivity studies is provided. A detailed description of all the studies is available in [16]

\section{A. Departure Routes}

To investigate effects of different departure-route combinations (see Fig. 1) the SIDs BIBOS6F and TOBAK2F are combined and termed northern routes $(\mathrm{N})$. The combination of the southerly routes ANEKI5F, DKB2F, and SOBRA1F is termed (S). In contrast to the actual use of the SIDs at Frankfurt airport here every SID is used with equal probabilities and the departure-route combinations are varied randomly. The SID route combinations NN, NS, SN, and SS (where the first letter designates the wake generator's route and the second letter is the follower aircraft's route) are filtered from the calculated scenarios. The respective sample sizes amount to 160,000, 240,000, 240,000 , and 360,000 pairings of departing aircraft. Although sample sizes of 160,000 scenarios do not guarantee completely converged results, the observed trends should be sufficiently robust. As a reference, a hypothetical straight departure route is also considered.

For the encounter statistics with crosswinds above $8 \mathrm{kt}$ displayed in Fig. 9 the differences between the SID combinations are quite prominent, because the encounters in ground proximity (which are independent of SID combinations) are already quite rare (see Fig. 4) and many encounters aloft are related to flight-path diversions. All encounter frequencies of the NS departure-route combination are smaller than in the reference scenario. For the SN SID combination the encounter frequencies are consistently higher. This can be attributed to the more frequent southwesterly winds, which transport the vortices from the south to the north routes. As a consequence for the SN SID combination only the close encounters are less frequent than in the reference scenario.

Note that the SS SID combinations feature significantly higher encounter frequencies than the other SID combinations. This again can be explained by the predominant southwesterly winds, which are headwinds with respect to the aircraft and which compensate the vortex-induced descent speed. The effect may be exacerbated by the resumption of climb when the aircraft reach the final climb speed at about $1800 \mathrm{ft}$. The NN SID combination that is used by default at
Frankfurt airport features consistently lower encounter frequencies compared with the reference scenario with the sole exception of the frequency of $\Gamma>350 \mathrm{~m}^{2} / \mathrm{s}$ and a/c-vortex distance of less than $2 \mathrm{~m}$.

The straight departure route resembles mostly the one of the NN SID combination but the encounter frequencies are even slightly lower for the straight departures and consistently lower than the encounter frequencies of the reference scenario. Obviously, changes of the flight direction contribute significantly to the encounter frequencies out of ground proximity.

As a result for a generic airport the SID combination study indicates that reduced departure separations could be supported by crosswinds above $8 \mathrm{kt}$ for a straight departure route. For diverging departure-route combinations the procedure could be refined by using only SID combinations where the leading aircraft is flying on the downwind SID.

\section{B. Wind Directions}

This section considers effects of wind directions on the encounter frequencies. Four different wind-direction sectors are distinguished: headwind, tailwind, crosswind from port side, and crosswind from starboard side. Here, the wind directions are defined with respect to the runway direction. So headwinds are blowing from $315^{\circ}<$ RWA $<45^{\circ}$, where RWA denotes the relative wind angle with respect to the runway direction. Winds from the starboard side correspond to the wind-direction range $45^{\circ}<\mathrm{RWA}<135^{\circ}$.

Table 2 lists the encounter frequencies dependent on the four different wind-direction sectors for the reference scenario. Headwind situations lead to the highest encounter probabilities, because headwind transport of the wake vortices may compensate wakevortex descent or even lead to rising wake vortices with respect to the generator aircraft trajectory. This effect increases encounter frequencies, because the medium-weight-class followers usually take off earlier than the leader and climb steeper than the leading aircraft and therefore usually fly above the wake vortices. In contrast, the encounter frequencies for tailwind situations are much lower (more than a factor of 5), because tailwinds support wake-vortex descent.
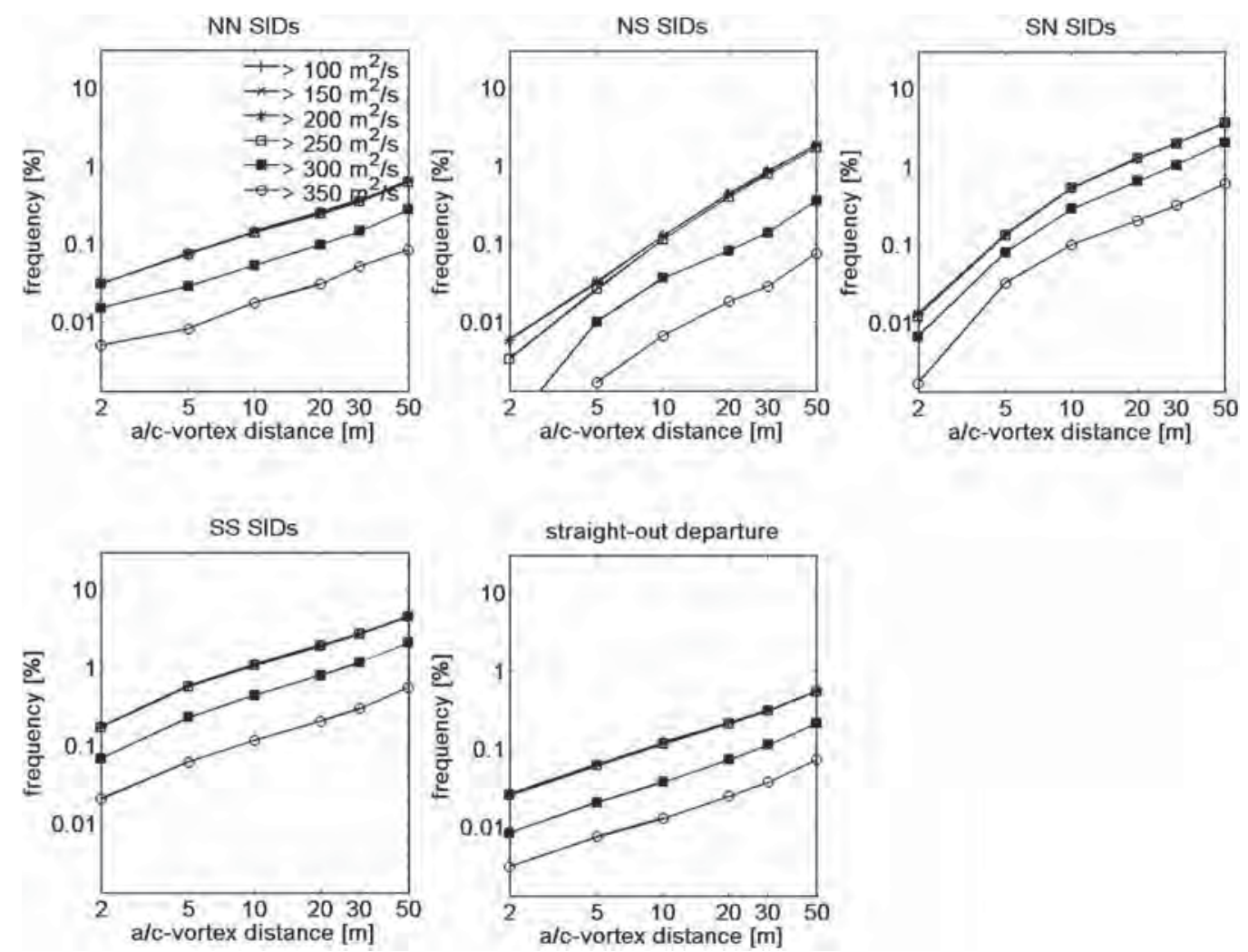

Fig. 9 Encounter frequency statistics of four different departure-route combinations and a straight departure route for aircraft separations of $60 \mathrm{~s}$ and crosswinds above 8 kt. 
Table 2 Encounter frequencies dependent on four different $90^{\circ}$ wind-direction sectors for the reference scenario

\begin{tabular}{|c|c|c|c|c|c|}
\hline & \multicolumn{5}{|c|}{ SID combined wind direction } \\
\hline & All & $\mathrm{NN}(16.0 \%)$ & NS $(24.0 \%)$ & $\mathrm{SN}(24.0 \%)$ & SS $(36.0 \%)$ \\
\hline CW port $(20.9 \%)$ & $5.2 \%$ & $4.6 \%$ & $4.3 \%$ & $5.3 \%$ & $6.1 \%$ \\
\hline CW starboard $(18.9 \%)$ & $1.7 \%$ & $1.6 \%$ & $1.6 \%$ & $1.5 \%$ & $1.9 \%$ \\
\hline Tailwind $(22.4 \%)$ & $2.5 \%$ & $2.3 \%$ & $2.1 \%$ & $2.4 \%$ & $2.9 \%$ \\
\hline Headwind $(37.8 \%)$ & $13.3 \%$ & $13.4 \%$ & $13.3 \%$ & $13.0 \%$ & $13.4 \%$ \\
\hline
\end{tabular}

aThe wind sector icons assume a flight direction from right to left.

However, the smallest encounter frequencies are observed for crosswinds from the starboard side. Here, the crosswinds close to the ground reduce encounter frequencies. With increasing height the wind direction turns, on average, to the right. Consequentially, a tailwind component is added to the crosswind, which supports vortex descent and thus reduces encounter frequencies aloft.

The turning of the wind direction with altitude is related to the concept of the Ekman spiral depicted in Fig. 10: Above the atmospheric boundary layer with a thickness on the order of $1 \mathrm{~km}$ the wind direction is mainly controlled by the equilibrium of the driving pressure gradient force and the Coriolis force. The resulting wind is called geostrophic wind. In the atmospheric boundary layer the friction force causes a deviation of the wind direction to the left (on the northern hemisphere).

Because of the same mechanism crosswinds from port side receive a headwind component with increasing height. As a consequence, the port crosswind situation leads to three times more encounters than the starboard-side crosswinds. Additionally, crosswinds from the port side also support encounters for departures of the leading aircraft on the southerly departure routes. There is also some weak trend that the strongest circulation values occur for the headwind encounters (not shown).

Table 3 lists the wind-direction effects for $60 \mathrm{~s}$ aircraft separations and crosswinds above $6 \mathrm{kt}$. Because cases with tailwinds above $5 \mathrm{kt}$ are excluded from operations, the wind sector for tailwinds has no contributions. The encounter frequencies for headwinds and for crosswinds from the port side are now almost identical. Considerable differences occur between the different departure-route combinations. Small encounter frequencies are observed for headwinds and crosswinds from the port side (southerly winds) for leading aircraft on the northern departure routes and, conversely, for crosswinds from the starboard (northerly winds) side for leading aircraft on the southern departure routes. Hence, encounters can be avoided if the crosswind after the turn transports the vortices away from the former flight track, i.e., southerly crosswinds are favorable for turns to the north.

The smallest encounter frequencies occur for crosswinds from the starboard side combined with the SN SID combination. Here, two favorable effects are combined: the turning of the crosswind to a

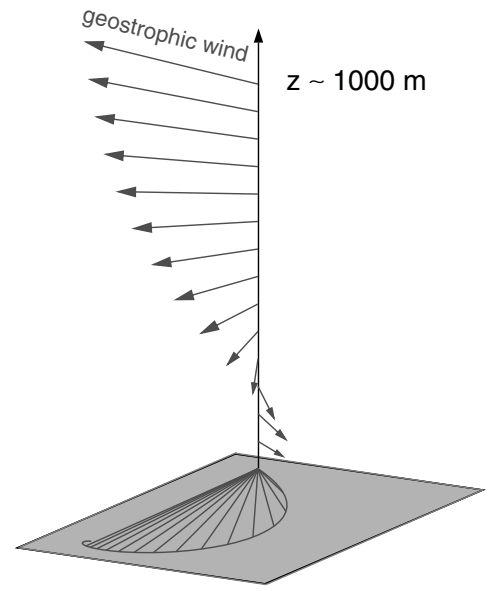

Fig. 10 Schematic sketch of Ekman spiral. tailwind at increasing altitudes and the fact that the vortex generating aircraft uses the downwind departure route. Crosswinds above $8 \mathrm{kt}$ show similar characteristics with further reduced encounter frequencies.

\section{Key Results of Remaining Studies}

1. Sample Size

It must be guaranteed that the sample size of the Monte Carlo simulations is sufficiently large to also provide converged simulation results for rare events. For this purpose, statistics of encounter frequencies derived from sample sizes of $10^{4}, 5 \times 10^{4}, 10^{5}, 2 \times 10^{5}$, $5 \times 10^{5}$, and $10^{6}$ departures of aircraft pairings have been analyzed for different scenarios. It was found that a reasonable representation of the frequencies of the most critical and rare encounters requires sample sizes of 500,000 departures of aircraft pairings. Therefore, the one-million-sample size used for the current investigations guarantees well-converged statistics.

\section{Operation Times}

By default, the meteorological data of the NOWVIV one-year database is employed only within the operational hours of Frankfurt airport (06:00-23:00). A comparison with $24 \mathrm{~h}$ operations indicates a minor increase of encounter frequencies for nocturnal meteorological conditions. This can potentially be explained by the reduced turbulence in the residual layer (which increases vortex lifetimes) and the increased temperature stratification (which reduces vortex descent).

\section{Flight-Path Adherence}

Deviations from nominal flight tracks in vertical and horizontal direction have been determined being on the order of $100 \mathrm{~m}$. Therefore, the sensitivity of encounter frequencies of the standard flight-path deviation model has been compared with a version in which these deviations were deactivated. The study indicates that the deactivation of aircraft trajectory deviations only slightly reduces the encounter frequencies.

\section{Pull-Away Effect}

In contrast to arrivals where a close-up effect, on average, reduces aircraft separations, an increase of average aircraft separations is expected for departures. The reason is that at a given time the leading aircraft has arrived in general already at a higher flight speed than the follower aircraft. The simulations indicate that the separation increases are spread between 0 to $3 \mathrm{NM}$ that is the minimum initial separation is never reduced. The pull-away effect is the more pronounced the more the initial aircraft separations are reduced.

\section{Wake-Vortex Model}

Wake-vortex modeling constitutes a very important element of WakeScene-D. Therefore, the statistics achieved with the D2P wakevortex model have been compared with results of the Deterministic Vortex Model (DVM) [26]. The two wake-vortex models deliver very similar characteristics of encounter altitude, the distance between follower aircraft and wake vortex, and vortex age. The circulation distributions exhibit different characteristics but almost identical ranges. In ground proximity the $\mathrm{D} 2 \mathrm{P}$ model predicts more 
Table 3 Encounter frequencies and corresponding circulation strengths dependent on four different $90^{\circ}$ wind-direction sectors for $60 \mathrm{~s}$ aircraft separations and crosswinds above $6 \mathrm{kt}$

\begin{tabular}{|c|c|c|c|c|c|}
\hline & \multicolumn{5}{|c|}{ SID combined wind direction } \\
\hline & All & $\mathrm{NN}(16.0 \%)$ & NS $(24.0 \%)$ & $\mathrm{SN}(24.0 \%)$ & SS $(36.0 \%)$ \\
\hline $\mathrm{CW}$ port $(38.0 \%)$ & $5.5 \%$ & $1.8 \%$ & $1.4 \%$ & $7.7 \%$ & $8.5 \%$ \\
\hline CW starboard (44.7\%) & $1.5 \%$ & $0.9 \%$ & $3.5 \%$ & $0.2 \%$ & $1.3 \%$ \\
\hline Tailwind (0\%) & - & - & - & - & - \\
\hline Headwind (17.2 \%) & $5.8 \%$ & $1.6 \%$ & $2.7 \%$ & $7.9 \%$ & $8.3 \%$ \\
\hline
\end{tabular}

pronounced vortex spreading. For the statistics of encounter strength and distance between aircraft and vortex similar characteristics are found. The corresponding deviations are naturally more pronounced for the rare encounters and reside typically within a range of 5 to $30 \%$. Because the encounter frequencies of equal strength vary between the different scenarios by up to almost 2 orders of magnitude, the agreement between the encounter statistics of the two wake-vortex models is considered as good. In particular, the conclusions derived from the synopsis of the encounter frequencies in Table 1 would be identical with the DVM wake-vortex predictions.

\section{Aircraft-Type Combinations/Takeoff Weight}

The encounter frequencies of the considered scenarios have been filtered to attribute the encounters to the 24 possible leader/follower combinations. As expected, encounters are avoided if the leading aircraft take off late and climb slowly, whereas the follower aircraft take off early with a steep climb rate. Thereby, the respective flight tracks are well separated. In contrast, if the leading aircraft take off early and climb steeply, whereas the follower aircraft take off relatively late, the resulting flight tracks may be close to each other, leading to high encounter probabilities. The same interrelations also apply to the takeoff-weight distributions (which correlate with takeoff positions and climb rates) within specific aircraft-type combinations.

\section{Comparison with Arrival Situation}

The comparison of the current reference scenario (see Fig. 2f) to WakeScene results for arrivals obeying the ICAO minimum separation of $5 \mathrm{NM}$ between heavy and medium aircraft in [9] indicates that encounters $\left(\Gamma>100 \mathrm{~m}^{2} / \mathrm{s}\right.$ and distances to the vortices below $30 \mathrm{~m}$ ) are 5.6 times more frequent for arrivals $(21.5 \%)$ than for departures $(3.8 \%)$. For approaches the accumulation of encounters within a height range below $300 \mathrm{ft}$ is about $95 \%$ even more pronounced. The reason for these differences can mainly be attributed to the much more pronounced spreading of aircraft trajectories for the departure situation that is caused by, e.g., large variations of rotation point and climb rate. Note that the considered departure and arrival scenarios cannot be directly compared, due to differences regarding sample size and traffic mix. Further, in the arrival simulations the aircraft are already installed on the glide slope, whereas for departures waypoints with diverging flight routes are considered.
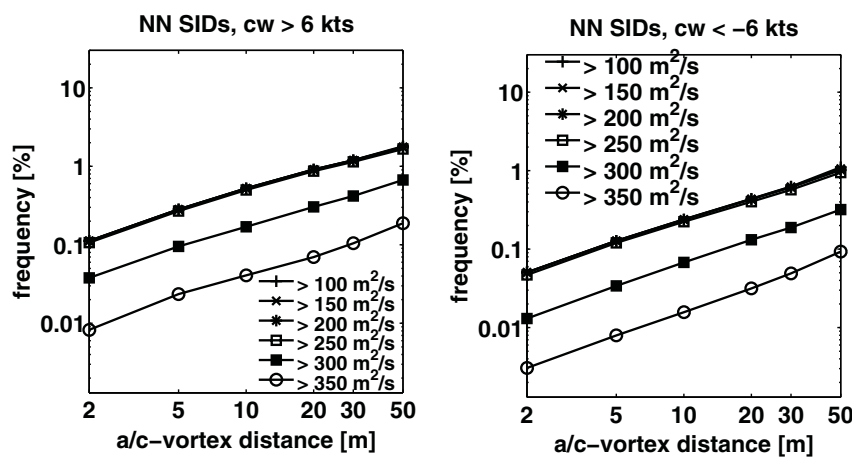

Fig. 11 Encounter frequencies for aircraft separations of $60 \mathrm{~s}$ and a crosswind threshold of $6 \mathrm{kt}$ (left, wind from port side) and for a crosswind threshold of $-6 \mathrm{kt}$ (right, wind from starboard side).

\section{Implementation of Lessons Learned}

This section investigates an advanced crosswind scenario that is based on the lessons learned from the sensitivity analysis. First, we restrict the analysis on the northern departure routes used by default at Frankfurt airport where encounters are relatively rare (see Sec. VI.A). Second, we differentiate crosswinds blowing from the port side and the starboard side of the departing aircraft (see Sec. VI.B). Encounter frequencies for $60 \mathrm{~s}$ departure separations and a crosswind threshold of $6 \mathrm{kt}$ are displayed in Fig. 11. For positive crosswinds (wind from port side, left plot) the worst-case encounter frequency of $0.0082 \%$ is higher than in the reference scenario (see Table 1). However, for crosswinds below $-6 \mathrm{kt}$ (wind from starboard side, right plot) the encounter frequencies of all circulation and distance thresholds are smaller than in the reference scenario (worstcase encounter frequency is $0.0031 \%$ ).

In conclusion, the consideration of the northern departure routes as used routinely at Frankfurt airport yields encounter frequencies below the reference scenario for all considered vortex distances and circulation strengths for crosswinds below $-6 \mathrm{kt}$ (wind from starboard side) and for crosswind magnitudes above $8 \mathrm{kt}$ (see Sec. VI.A). The assessment of the related encounter risks with VESA leads to the same conclusions [27].

\section{Conclusions}

WakeScene-D is a software package to determine wake-vortex encounter probabilities for departures. The severity of potential encounters identified by WakeScene-D can subsequently be evaluated with VESA $[10,11]$. In this paper, the components of WakeScene-D that model traffic mix, aircraft trajectories, meteorological conditions, wake-vortex evolution, and potential hazard area are first briefly introduced. Then various investigated scenarios are discussed that shall support the identification of suitable crosswind criteria that allow reducing aircraft separations for departures.

Measured vortex tracks of about 10,000 departures from runway 25R of Frankfurt airport are compared with WakeScene-D simulations. For lateral vortex transport, which for crosswind departures constitutes the most important quantity, good agreement between the characteristics of measurement and simulation is achieved. This good agreement indicates that WakeScene-D is an instrument that allows investigating realistic wake-vortex behavior in domains and height ranges that are far out of reach of measurements.

Monte Carlo simulations of the Frankfurt traffic mix with a sample size of $1,000,000$ cases indicate that for current operations $66 \%$ of the potential encounters are restricted to heights below $300 \mathrm{ft}$ above ground. Within this altitude range clearance of the flight corridor by descent and advection of the vortices is restricted: stalling or rebounding vortices may not clear the flight path vertically and weak crosswinds may be compensated by vortex-induced lateral transport [20]. Further, minor peaks at altitudes of 1300 and $1800 \mathrm{ft}$ occur that can be attributed to flight-path diversions (change of climb rate and heading) in combination with adverse wind conditions (headwind and crosswind) that increase the encounter risk compared with approximately parallel flight of the leader and follower aircraft. For example, increased encounter frequencies are observed when the leading aircraft conducts a turn toward the main wind direction. The resulting headwind component may compensate wake-vortex 
descent and may advect the vortex trail into the flight path of the follower aircraft.

Statistics of encounter frequencies and encounter conditions have been established for 60 and $90 \mathrm{~s}$ departure separations and minimum crosswinds from 0 to $10 \mathrm{kt}$ in $2 \mathrm{kt}$ increments, respectively. The reduction of aircraft separations from 120 to $60 \mathrm{~s}$ approximately triples the number of encounters, whereas the fraction of strong encounters increases due to the reduced time for vortex decay.

If aircraft separations are reduced to $60 \mathrm{~s}$ and crosswinds at $10 \mathrm{~m}$ height above ground exceed a threshold of $8 \mathrm{kt}$, the overall frequency of potential encounters of $3.1 \%$ clearly is falling below the corresponding frequency of $7.0 \%$ of the reference scenario. The strong crosswind in ground proximity very efficiently reduces the encounters below $300 \mathrm{ft}$ from $4.6 \%$ in the reference scenario to $0.0056 \%$. Unfortunately, the $10 \mathrm{~m}$ crosswind criterion alone is not sufficient to reduce encounters that are related to flight-path diversions along the departure routes. Because of the by $50 \%$ reduced time for vortex transport and decay, encounters with circulations stronger than $350 \mathrm{~m}^{2} / \mathrm{s}$ are still two to four times more frequent than in the reference scenario.

An investigation of wind-direction effects on the encounter frequencies reveals an intriguing phenomenon: Headwind situations lead to the highest encounter probabilities, because headwind transport of the wake vortices may compensate wake-vortex descent or even lead to rising wake vortices with respect to the generator aircraft trajectory. This effect increases encounter frequencies, because the medium-weight-class followers usually take off earlier and climb steeper than the leading aircraft and therefore usually fly above the wake vortices. In contrast, the encounter frequencies for tailwind situations are much lower, because tailwinds support wakevortex descent.

However, the beneficial effects of crosswinds are not symmetric. The smallest encounter frequencies are observed for crosswinds from the starboard side. Here, the crosswinds close to the ground reduce encounter frequencies. With increasing height the wind direction turns, on average, to the right. Consequentially, a tailwind component is added to the crosswind, which supports relative vortex descent and thus reduces encounter frequencies aloft. This turning of the wind direction with height is related to the concept of the Ekman spiral, which describes the resulting wind direction in the atmospheric boundary layer by equilibrium of the driving pressure gradient force, the Coriolis force, and the friction force. Because of the same mechanism crosswinds from port side receive a headwind component with increasing height. As a consequence, the port crosswind situation leads to significantly more encounters than the starboard-side crosswinds.

From a WakeScene-D perspective it can be concluded that for $60 \mathrm{~s}$ departure separations along the northern departure routes as used routinely at Frankfurt airport, acceptable encounter frequencies are found for crosswinds below $-6 \mathrm{kt}$ (wind from starboard side) and for crosswind magnitudes above $8 \mathrm{kt}$. The respective assessment of the related encounter risks with VESA also leads to the same conclusions for straight departure routes [27]. Crosswind departure procedures could be refined by using only departure-route combinations where the leading aircraft is flying on the downwind route.

Crosswind transport certainly is the most effective mechanism to clear a flight corridor from wake vortices. However, the applicability of purely crosswind based wake-vortex advisory systems covering vertically extended domains is impeded by the veering wind with altitude. As a consequence, either the flight tracks of subsequent aircraft must be already separated at quite low altitudes such that the crosswind does not change significantly within the considered height ranges or the advisory system must also consider vortex descent and/ or vortex decay either explicitly or implicitly as in the presented concept.

\section{Acknowledgments}

The financial support from the European Union project Crosswind-Reduced Separations for Departure Operation (CREDOS; AST5-CT-2006-030837) and from the DLR, German
Aerospace Center project Wirbelschleppe is greatly acknowledged. Thanks are addressed to many CREDOS colleagues for numerous discussions and valuable comments.

\section{References}

[1] "Wake Vortex Research Needs for Improved Wake Vortex Separation Ruling and Reduced Wake Signatures," National Aerospace Lab., NLR-CR-2006-171, Amsterdam, Mar. 2006.

[2] "Procedures for Air Navigation Services-Air Traffic Management," International Civil Aviation Organization, Doc. 4444, ATM/501, Montreal, 2001.

[3] Gerz, T., Holzäpfel, F., Bryant, W., Köpp, F., Frech, M., Tafferner, A., and Winckelmans, G., "Research Towards a Wake-Vortex Advisory System for Optimal Aircraft Spacing," Comptes Rendus Physique, Vol. 6, Nos. 4-5, 2005, pp. 501-523. doi:10.1016/j.crhy.2005.06.002

[4] Hallock, J. N., Greene, G. C., and Burnham, D. C., "Wake Vortex Research-A Retrospective Look," Air Traffic Control Quarterly, Vol. 6, No. 3, 1998, pp. 161-178.

[5] de Bruin, A. C., Speijker, L. J. P., Moet, H., Krag, B., Luckner, R., and Mason, S., "S-Wake-Assessment of Wake Vortex Safety," National Aerospace Lab., NLR-TP-2003-243, Amsterdam, 2003.

[6] Frech, M., and Zinner, T., "Concept of Wake Vortex Behavior Classes,' Journal of Aircraft, Vol. 41, No. 3, 2004, pp. 564-570. doi: $10.2514 / 1.55$

[7] Frech, M., and Holzäpfel, F., "Skill of an Aircraft Wake-Vortex Model Using Weather Prediction and Observation," Journal of Aircraft, Vol. 45, No. 2, 2008, pp. 461-470. doi: $10.2514 / 1.28983$

[8] Holzäpfel, F., Kladetzke, J., Amelsberg, S., Lenz, H., Schwarz, C., and De Visscher, I., "Aircraft Wake Vortex Scenarios Simulation Package for Takeoff and Departure," Journal of Aircraft, Vol. 46, No. 2, 2009 pp. 713-717. doi:10.2514/1.39346; also AIAA Paper 2008-8921.

[9] Holzäpfel, F., Frech, M., Gerz, T., Tafferner, A., Hahn, K.-U., Schwarz, C., Joos, H.-D., Korn, B., Lenz, H., Luckner, R., and Höhne, G., "Aircraft Wake Vortex Scenarios Simulation Package-WakeScene," Aerospace Science and Technology, Vol. 13, No. 1, 2009, pp. 1-11. doi:10.1016/j.ast.2007.09.008

[10] Höhne, G., Luckner, R., and Fuhrmann, M., "Critical Wake Vortex Encounter Scenarios," Aerospace Science and Technology, Vol. 8, No. 8, 2004, pp. 689-701. doi:10.1016/j.ast.2004.07.005

[11] Luckner, R., Höhne, G., and Fuhrmann, M., "Hazard Criteria for Wake Vortex Encounters During Approach," Aerospace Science and Technology, Vol. 8, No. 8, 2004, pp. 673-687. doi: $10.1016 /$ j.ast.2004.06.008

[12] Joos, H.-D., Bals, J., Looye, G., Schnepper, K., and Varga, A., "A MultiObjective Optimisation Based Software Environment for Control Systems Design," Proceedings of the 2002 IEEE International Symposium on Computer Aided Control Systems Design, IEEE Press, Piscataway, NJ, 2002, pp. 7-14. doi:10.1109/CACSD.2002.1036921.

[13] Speijker, L. J. P., Kos, J., Blom, H. A. P., and van Baren, G. B. "Probabilistic Wake Vortex Safety Assessment to Evaluate Separation Distances for ATM Operations, 22nd International Congress of Aeronautical Sciences, 2000, Paper 652; also National Aerospace Lab., NLR-TP-2000-326, Amsterdam, Sept. 2000.

[14] Speijker, L. J. P., Vidal, A., Barbaresco, F., Frech, M., Barny, H., and Winckelmans, G., "ATC-Wake: Integrated Wake Vortex Safety \& Capacity System," Journal of Air Traffic Control, Vol. 49, No. 1, 2007, pp. $17-32$.

[15] Holzäpfel, F., and Kladetzke, J., "Assessment of Wake Vortex Encounter Probabilities for Crosswind Departure Scenarios," CEAS 2009 European Air and Space Conference, Manchester, England, U.K., 26-29 Oct. 2009.

[16] Holzäpfel, F., Kladetzke, J., "Wake Vortex Encounters During Takeoff \& Departure: Sensitivity Analysis and Worst Case Search," DLR, German Aerospace Center, Inst. of Atmospheric Physics, Rept. D3-9, Oberpfaffenhofen, Germany, 5 Nov. 2009.

[17] Anon., "Frankfurt Airport Luftverkehrsstatistik 2006," Fraport AG, Frankfurt am Main, Germany, 2007.

[18] Amelsberg, S., and Luckner, R., "Parametric Aircraft Trajectory Model for Takeoff and Departure," 1st CEAS European Air and Space Conference, CEAS Paper 2007-273, Sept. 2007.

[19] Holzäpfel, F., "Probabilistic Two-Phase Wake Vortex Decay and Transport Model," Journal of Aircraft, Vol. 40, No. 2, 2003, 
pp. $323-331$.

doi: $10.2514 / 2.3096$

[20] Holzäpfel, F., and Steen, M., "Aircraft Wake-Vortex Evolution in Ground Proximity: Analysis and Parameterization," AIAA Journal, Vol. 45, No. 1, 2007, pp. 218-227. doi: $10.2514 / 1.23917$

[21] Frech, M., Holzäpfel, F., Tafferner, A., and Gerz, T., "High-Resolution Weather Data Base for the Terminal Area of Frankfurt Airport," Journal of Applied Meteorology and Climatology, Vol. 46, No. 11, 2007, pp. 1913-1932.

doi:10.1175/2007JAMC1513.

[22] Schwarz, C. W., and Hahn, K.-U., "Full-Flight Simulator Study for Wake Vortex Hazard Area Investigation," Aerospace Science and Technology, Vol. 10, No. 2, 2006, pp. 136-143.

doi:10.1016/j.ast.2005.09.005

[23] Dengler, K., and Wiegele, A., "EDDF-1 Data Collection Campaign
Report," DLR, German Aerospace Center, Rept. D2-1, Oberpfaffenhofen, Germany, 7 Feb. 2008.

[24] De Visscher, I., Bricteux, L., Karampelas, S., Winckelmans, G., Holzäpfel, F., Baumann, R., Roblin, Y., and Schröder, K., "EDDF-2 Database Analysis and Performance Assessment of the Wake Vortex Models on the EDDF-1 and EDDF-2 Databases," Univ. Catholique de Louvain, Rept. D2-5, Louvain-la Neuve, Belgium, 4 June 2009.

[25] Konopka, J., and Fischer, H., "EDDF-2 Data Collection Campaign Report," DFS Deutsche Flugsicherung, Rept. D2-4, Langen, Germany, 11 Nov. 2008.

[26] Winckelmans, G., Duquesne, T., Treve, V., Desenfans, O., and Bricteux, L., "Summary Description of the Models Used in the Vortex Forecast System (VFS)," Univ. Catholique de Louvain, Louvain-la Neuve, Belgium, April 2005.

[27] Kauertz, S., "Workpackage 3 Final Report," EUROCONTROL, Rept. D3-11, 25 Nov. 2009. 